\title{
A cross-sectional study of swine influenza in intensive and extensive farms in the northeastern region of the state of São Paulo, Brazil
}

\author{
Henrique Meiroz de Souza Almeida ${ }^{1}$ Gabriel Yuri Storino ${ }^{1}$ Daniele Araújo Pereira ${ }^{1}$. \\ Igor Renan Honorato Gatto ${ }^{1}$ - Luis Antonio Mathias ${ }^{1}$ • Hélio José Montassier ${ }^{1}$ • \\ Luís Guilherme de Oliveira ${ }^{1}$
}

Received: 3 June 2016 / Accepted: 7 September 2016 / Published online: 16 September 2016

(C) Springer Science+Business Media Dordrecht 2016

\begin{abstract}
Swine influenza (SI) is a seasonal infectious disease highly important to the world pig industry. Loss of daily weight gain, increased costs for the prevention and treatment of secondary infections are the main economic losses associated with the presence of this disease. However, some epidemiological features of SI remain quite unclear. This study focused on assessing the prevalence of swine influenza virus (SIV) infection in intensive and extensive pig herds and associating risk factors. A set of 601 blood samples of five intensive farrow-to-finish farms and 361 blood samples from 56 extensive farms were analyzed using an indirect ELISA kit CIVTEST SUIS INFLUENZA®, Hipra (Amer, Spain), in order to detect anti-SIV antibodies. In total, $24.13 \%$ of samples from intensive herds were positive, while no positive samples were detected in extensive rearing herds. Sow and weaning piglets had the highest prevalence values. In the intensive rearing system, occurrence of reproductive disorders and exposure to recently introduced animals were positively associated with the disease occurrence in swine herds. The findings highlight the importance of sows in the epidemiology of the disease and bring information about risk factors involved in the occurrence of swine influenza in intensive herds.
\end{abstract}

Keywords Epidemiology · Pigs · Orthmyxoviridae . ELISA · SIV · Porcine respiratory disease complex

Luís Guilherme de Oliveira

luis.guilherme@fcav.unesp.br

1 Faculty of Agricultural and Veterinary Sciences, São Paulo State University (UNESP), Via de Acesso prof. Paulo Donato Castellane s/n, 14884-900 Jaboticabal, São Paulo, Brazil

\section{Introduction}

The swine influenza (SI) is a viral infectious disease that has great impact in the pig industry worldwide, mainly for being one of the most prevalent respiratory diseases in swine herds. The causative agent of SI is the swine influenza virus (SIV) which belongs to Orthomyxoviridae family and exists in three main different genotypes: H1N1, H2N1, and H3N2 (SimonGrifé et al., 2011) These viruses are endemic in several pigproducing regions, and epidemic outbreaks of SIV infection often occur in naïve pig herds (Brown, 2000). Additionally, SIV is one of the agents involved in the porcine respiratory diseases complex (Brown, 2000; Thacker, 2001; LópezRobles et al. 2014.

The influenza infection in swine usually results in acute respiratory signs, fever, anorexia, apathy, conjunctivitis, and nasal discharge (Vincent et al., 2008). When outbreaks occur in a naive population, the disease presents high morbidity and low mortality rates (Olsen, 2002). Thus, several other economic losses are associated with the disease such as reduction in the daily weight gain and increased costs with prevention and treatment of secondary infections (Van Reeth et al., 2012). In addition, piglets born from positive sows seemed to gain less weight, mainly in the second half of the finishing period, when compared to piglets from naïve sows (Loeffen et al. 2003a).

Despite being present in the main swine-producing regions in Brazil, few data is available about the prevalence of swine influenza in Brazilian herds (Schaefer et al., 2011). The first report on the isolation of SIV from oral cavity of naturally infected swine occurred in the state of São Paulo only in 2006 (Mancini et al., 2006). Recent studies have identified the SIV in industrial and wild pig herds (Biondo et al., 2014; Schaefer et al., 2015). Thus, a study performed in 48 intensive pig farms in the southern region, found that around $30 \%$ of them had 
$95 \%$ of positive animals, resulting in a total animal level prevalence of $78.1 \%$, suggesting that the disease might be widespread in some Brazilian regions (Ciacci-Zanella et al., 2015).

On the other hand, as far as the authors know, published data about prevalence and the role of extensive pig farms in the swine influenza epidemiology are very scarce. This study focused on detecting/comparing the prevalence of SIV infection in intensive and extensive swine-rearing farms and associating risk factors for the infection in the northeastern region of the state of São Paulo.

\section{Material and methods}

\section{Sample design and collection}

Five farrow-to-finish intensive pig farms were selected in order to accomplish the aim of this research. The criteria for farm inclusion was sow herd larger than 200 animals and the voluntary acceptance of the owner for inclusion in the study and the geographical region, altogether characterizing a convenience sample. All sampling sites had intensive producing system and were located in municipalities of Jaboticabal, Monte Alto, Bebedouro, and Guariba, in the northeastern region of the state of São Paulo. A fixed number of 30 blood samples was collected per each age group present in the farm. Grossly, each farm had approximately 120 blood samples collected, totalizing 601 samples from intensive farms.

Fifty-six extensive herds had samples collected in order to assess the swine influenza prevalence in this rearing system. The criteria used for the inclusion in the study was poor sanitary conditions and low adoption of biosecurity measures in the production site, since the animals of this type of farms were our target population. Thus, the owner's voluntary acceptance for being included in the study and the geographical location were also taken into account, consequently featuring a convenience sample.

All samples from extensive farms were collected during the years of 2014 and 2015, in 12 municipalities (Jaboticabal, Taiúva, Taiaçu, Guariba, Pradópolis, Ibitinga, Borborema, Itápolis, Motuca, Monte Alto, Taquaritinga, and Santa Ernestina) located in the northeastern region of the state of São Paulo.

If the herd had five or less animals, all had their blood samples collected; however, in larger herds, we randomly sampled $10 \%$ of the animals. In order to achieve a representative sample size, we used the following equation (Thrusfield, 2010):

$n=\frac{z^{2} \cdot p \cdot q}{d^{2}}$

$n=$ sample size, $Z=$ normal standard deviation, $p=$ disease's expected prevalence, $q=1-\mathrm{p}$; and $d=$ maximum admitted error value. An expected prevalence of $1 \%$ was estimated since there is no data about swine influenza in the sampled region that could provide a more accurate value. The obtained value $(n)$ was adjusted (na) to the regional population size $(N)$, by the equation (Thrusfield, 2010):

$n a=\frac{n \times N}{n+N}$

The $N$ value used was 4100 animals, according to the regional swine population published in the last São Paulo state animal census (São Paulo, 2008). None of the intensive or extensive farms reported occurrence of clinical signs of respiratory disease resembling SI in the herds.

All blood samples were collected through jugular puncture using disposable syringes and needles. At laboratory site, the samples had the serum separated by centrifugation and stored in plastic microtubes at $-20^{\circ} \mathrm{C}$ until use.

\section{ELISA test}

To assess the presence of anti-SIV antibodies, the commercial indirect ELISA kit CIVTEST SUIS INFLUENZA®, Hipra (Amer-Girona, Spain) was used, as recommended by Simon-Grifé et al. (2011). The kit used antigens of H1N1 strain of SIV, which also presented cross-reaction with other strains such as H1N2 and H3N2 according to the manufacturer, though H1N1-positive sera were more frequently detected as positive than H1N2- or H3N2-positive (Simon-Grifé et al., 2011) were. The IRPC (Relative Index $\times 100$ ) calculation used the optical density (OD) values obtained, as shown by the following equation given by the manufacturer:

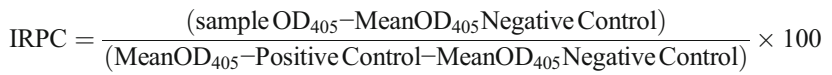

The positive samples were those which presented an IRPC value $>20.0$, consequently an IRPC value $\leq 20.0$ was indicative of negative result. Both the test performance and result interpretation were according to the guidelines established by the kit's manufacturer.

\section{Risk factor association}

In order to detect risk factors associated with the occurrence of swine influenza at herd and at animal level, we gathered epidemiological data through the application of a questionnaire to the farm owner at the sampling moment. Information regarding the type of rearing system (extensive or intensive), recent introduction of sows in the herd (last 6 months), and the occurrence of reproductive disorders were tabled and further used in the risk factor analysis. 


\section{Data analysis}

Since the age groups had different population among the farms and the sample number was fixed ( 30 samples per strata), the prevalence of positive samples had to be adjusted to the age group population size in order to achieve a representative and undistorted figure. To this, we transformed the prevalence of positive samples into the expected number of positive animals using each individual age group population. In the next step, the proportion that the expected number of positive animals represented in the farm's total swine population was calculated and assumed as the adjusted prevalence value for that age group.

The $95 \%$ confidence interval calculation was according to Wilson's method (for values lower than $5 \%$ ) for each adjusted farm level prevalence value. To estimate the odds ratio (OR) values at animal level, at herd level and to perform logistic regression analysis, we used the software Epi Info version 7.1.1.14.

\section{Results}

\section{Prevalence results}

All prevalence values found for the different age groups of the intensive swine farms and the corresponding $95 \% \mathrm{CI}$ are in Table 1 . The overall prevalence found in the intensive farms was $24.13 \%$ (145/601; $95 \%$ CI 20.71-27.55\%).

In all intensive farms, the age groups that presented the highest prevalence values were the sow and weaning piglets group. The chi-squared analysis showed the presence of significant difference between the age groups $\left(X^{2}=107.6901\right.$; $p<0.01)$ and between the herds $\left(X^{2}=102.9594 ; p<0.01\right)$. The prevalence of SIV infection in extensive pig farms was $0 \%$, since no positive sample was detected in the ELISA out of 361 serum samples tested.

\section{Risk factor association}

When analyzing at animal level, being exposed to animals recently introduced in the herd had a positive association with the occurrence of influenza, OR $=4.49$ (95\% CI 2.91-6.93; corrected $\left.X^{2}=51.16 ; p<0.05\right)$. When comparing the disease cases between intensive and extensive farming animals, the chi-squared test showed a significant higher occurrence in animals of intensive farms (corrected $X^{2}=91.42 ; p<0.01$ ); however, it was not possible to estimate the OR value since the prevalence value in extensive farm animals was $0 \%$.

Assessing the herd level risk factors, the occurrence of reproductive disorders presented a positive association with influenza cases, OR $=10.93$ (95 \% CI 1.13-105.80; $p<0.05)$. Thus, the prevalence in intensive farms was again significantly higher $\left(X^{2}=60.0 ; p<0.05\right)$ than in extensive farms. When creating a logistic regression model, the only variable that remained significant in the model was occurrence of reproductive disorders $\mathrm{OR}=12.41$ (95\% CI 1.23-125.32, $p<0.05$ ), likelihood ratio test $6.79, p<0.05$.

\section{Discussion}

The SIV prevalence found in intensive farms $(24.13 \%)$ is relatively low if compared to those found in previous studies $32.3 \%$ in France (Fablet et al., 2013), 55 \% in Mexico (LópezRobles et al., 2014), $62.3 \%$ in Spain (Simon-Grifé et al., 2011), $78.1 \%$ in southern region of Brazil (Ciacci-Zanella et al., 2015), and $39.12 \%$ in South Korea (Jeong et al., 2007).

Another study performed by Dias et al. (2015), using the hemagglutination inhibition (HI) test, detected in swine from the state of Minas Gerais, $26.23 \%$ of infected animals by the strain H1N1pdm09 and $1.57 \%$ by strain H2N3, also, at herd level the prevalence values found were 96.6 and $13.2 \%$, respectively. A similar prevalence was found by this research, even though the agreement rate between the HI test and the same ELISA was considered only fair by Simon-Grifé et al. (2011). On the other hand, it is difficult to compare prevalence rates obtained by different studies, since each one has its own particular characteristics such as the production system employed or the herd immune status (Ciacci-Zanella et al., 2015).

The prevalence of SIV strains varied among different regions and herds (Dias et al., 2015). Thus, the ELISA used in this study had higher power to detect anti-H1N1 antibodies $(S=100 \%)$ than anti-H1N2 and H3N2 antibodies $S=86.9$ and $73.4 \%$, respectively (Simon-Grifé et al., 2011). Consequently, it is possible that differences between the antigen used in the ELISA and the antigen of the circulating strains in the swine population sampled could have limited the diagnostic power of the test. A further study using an ELISA kit based on a more conserved antigen such as nucleoproteins would be interesting in order to avoid this type of limitation and detect values that are more accurate.

In this research, recent introduction of sows from external sources was pointed out as a risk factor for the occurrence of influenza $(\mathrm{OR}=4.49,2.91-6.93 ; p<0.05)$ at animal level. This fact agrees with the findings of Poljak et al. (2008), who showed that farms which had an external source of gilts presented an OR 4.62 (1.14-20.91), $p=0.03$ for influenza. The introduction of SIV-infected animals is commonly associated with occurrence of disease cases in naïve herds (Van Reeth et al., 2012), and World Organization for Animal Health (2009) points it as the main cause of outbreaks in swine herds. Simon-Grifé et al. (2011) also significantly associated an increase in influenza cases in herds with high replacement rate of sows. 
Table 1 Data of the five sampled farms containing total of sampled collected per age group. The prevalence found using ELISA and the overall prevalence within the farm with the respective $95 \% \mathrm{CI}$

\begin{tabular}{|c|c|c|c|c|c|c|c|c|}
\hline $\begin{array}{l}\text { Farm } \\
\text { identification }\end{array}$ & Age group & $\begin{array}{l}\text { Age group } \\
\text { total population }\end{array}$ & $\begin{array}{l}\text { No. of positive } \\
\text { samples }\end{array}$ & $\begin{array}{l}\text { No. of animals } \\
\text { sampled }\end{array}$ & $\begin{array}{l}\text { Prevalence } \\
\text { within the } \\
\text { sample }(\%)\end{array}$ & $\begin{array}{l}\text { Expected no. of } \\
\text { positive animals } \\
\text { in the age group }\end{array}$ & $\begin{array}{l}\text { Adjusted } \\
\text { prevalence } \\
\text { value }(\%)\end{array}$ & $95 \%$ CI \\
\hline \multirow[t]{7}{*}{ Farm 01} & Weaning & 90 & 36 & 38 & 94.74 & 85.26 & 5.30 & \\
\hline & Nursery & 300 & 2 & 30 & 6.67 & 20 & 1.24 & \\
\hline & Finisher & 1000 & 0 & 30 & 0.00 & 0 & 0 & \\
\hline & Sows & 220 & 19 & 26 & 73.08 & 160.77 & 9.98 & \\
\hline & Total & 1610 & 57 & 124 & 45.97 & 266.3 & 16.52 & $9.99-23.06$ \\
\hline & Weaning & 500 & 9 & 30 & 30.00 & 150 & 5.08 & \\
\hline & Nursery & 1100 & 0 & 30 & 0.00 & 0 & 0 & \\
\hline \multirow[t]{5}{*}{ Farm 02} & Finisher & 1000 & 0 & 30 & 0.00 & 0 & 0 & \\
\hline & Sows & 350 & 15 & 33 & 45.45 & 159.09 & 5.39 & \\
\hline & Total & 2950 & 24 & 123 & 19.51 & 309.09 & 10.48 & $5.06-15.89$ \\
\hline & Weaning & 60 & 0 & 33 & 0.00 & 0 & 0 & \\
\hline & Nursery & 51 & 0 & 29 & 0.00 & 0 & 0 & \\
\hline \multirow[t]{5}{*}{ Farm 03} & Finisher & 120 & 0 & 30 & 0.00 & 0 & 0 & \\
\hline & Sows & 60 & 6 & 30 & 20.00 & 12 & 4.12 & \\
\hline & Total & 291 & 6 & 122 & 4.92 & 12 & 4.12 & $5.95-7.65$ \\
\hline & Weaning & 280 & 13 & 28 & 46.43 & 130 & 11.02 & \\
\hline & Nursery & 280 & 5 & 20 & 25.00 & 70 & 5.93 & \\
\hline \multirow[t]{5}{*}{ Farm 04} & Finisher & 450 & 5 & 30 & 16.67 & 75 & 6.35 & \\
\hline & Sows & 170 & 18 & 30 & 60.00 & 102 & 8.64 & \\
\hline & Total & 1180 & 41 & 108 & 37.96 & 377 & 31.95 & $23.15-40.74$ \\
\hline & Weaning & 73 & 4 & 30 & 13.33 & 9.73 & 2.37 & \\
\hline & Nursery & 48 & 0 & 30 & 0.00 & 0 & 0 & \\
\hline \multirow[t]{3}{*}{ Farm 05} & Finisher & 120 & 0 & 32 & 0.00 & 0 & 0 & \\
\hline & Sows & 170 & 1 & 32 & 3.13 & 5.31 & 1.29 & \\
\hline & Total & 411 & 5 & 124 & 4.03 & 15.04 & 3.66 & $3.55-6.97$ \\
\hline
\end{tabular}

Moreover, other factors play important role in the SIV dynamics within a herd. The SIV is highly contagious and easily transmitted through aerosols, nose-to-nose contact, and direct contact with nasal secretions (World Organization for Animal Health, 2009; Corzo et al., 2013). In intensive rearing farms, the high density of animals per pen exposes susceptible animals to such interactions more often than in extensive farms.

There are evidences that high animal density in farms also relates to high prevalence of SIV infections in the herd (Dias et al., 2015). The odds of a herd being infected increases as the density of pigs in the herd also increases (Poljak et al., 2008). Other paper showed that large number of pigs per pen had an OR $3.2(1.2-8.6 ; p<0.05)$ for having H1N1-infected animals (Fablet et al., 2013). This is probably why in this paper, the chi-squared test pointed out, at animal and at herd level, significantly higher prevalence in intensive herd's animals when compared to extensive herd animals, even though it was not possible to estimate the OR value.
The absence of positive animals in extensive farms could be explained by particular features of such farms, since the animals are reared in an extensive way, the transmission of the SIV by direct contact or aerosol could be reduced and more unlike to happen. The assessment of influenza virus concentration in closed barn's airspace proved it an important issue in the disease's epidemiology (Corzo et al., 2013). Moreover, the general lack of technification reduces the quantity of people in direct contact with animals and the entrance of vehicles in this type of farm, and both are risk factors for the introduction of the SIV infection in naïve populations (Poljak et al., 2008).

None of the sampled farms vaccinated the sows against swine influenza or reported the occurrence of disease with clinical signs resembling SIV in the animals at the sampling moment. Consequently, probably all antibodies detected by the ELISA test probably were indicative of current or past SIV infections. 
In addition, the chi-squared analysis showed the presence of significant difference between the age groups $\left(X^{2}=107.6901 ; p<0.01\right)$ in intensive farms. The sow and the weaned piglets group had the highest prevalence in all sampled farms. The role played by sows in the production system is of utter importance, since these animals stay for longer periods in the herd and consequently have more odds of being infected by ubiquitous agents, like SIV, during their life period (Simon-Grifé et al., 2011). Regarding weaning piglets, we do not discard the possibility of the high prevalence values found were due to maternal-derived antibodies, once Loeffen et al. (2003b) showed that infection prior 8 weeks of age was unlikely.

Sows were already identified as SIV reservoirs in swine herds (Loeffen et al. 2003a). Such facts might explain why this age group had the highest prevalence values in all five intensive farms, when compared to the finisher and nursery age groups. The odds of a pig becoming infected increases in farrow-to-finish farm (Jeong et al., 2007; Poljak et al., 2008), and it is common to have an external replacement gilts source, a fact that was formerly associated in this study with the introduction of swine influenza in the herd. Moreover, indirect exposure of finishing and nursery piglets to SIV from sows or weaned piglets is easier in farrow-to-finish herds (Loeffen et al., 2009).

At herd level, the occurrence of reproductive disorders was associated with influenza cases within the herd OR = 10.93 (95\%CI $1.13-105.80 ; p<0.05)$ and remained significant in a multivariate logistic regression. In this sense, abortions in infected pregnant sows may occur because of fever (World Organization for Animal Health, 2009). Thus, experimentally infected pregnant gilts had at least two or three stillborn piglets, even though there is still no evidence of the SIV crossing the placenta (Wesley, 2004).

In conclusion, the occurrence of swine influenza in the herds was successfully associated with intensive rearing system, exposure to recently introduced animals, and presence of reproductive disorders. Thus, high prevalence found in sows of intensive farms highlights the importance of this age group as reservoir of SIV in the disease's epidemiology.

Acknowledgments We would like to acknowledge the Brazilian National Research Council (CNpq) and PROPe-Pró-Reitoria de Pesquisa of São Paulo State University for the financial support granted (Primeiros Projetos-Edital 12/2015-PROPe/UNESP).

\section{Compliance with ethical standards}

Conflict of interest The authors declare that they have no conflict of interest.

Ethics committee approval The institution's ethics committee approved this research and the certificate registered under the protocol no. 07998/14 on 8th of May of 2014.

\section{References}

Biondo, N., Schaefer, R., Gava, D., Cantão, M.E., Silveira, S., Mores, M.A.Z., 2014. Genomic analysis of influenza A virus from captive wild boars in Brazil reveals a human-like H1N2 influenza virus. Veterinary Microbiology 168, pp.34-40.

Brown, I. H., 2000. The epidemiology and evolution of influenza viruses in pigs. Veterinary Microbiology 74, 29-46.

Ciacci-Zanella, J. R., Schaefer, R., Gava, D., Haach, V., Cantão, M. E., Coldebella, A., 2015. Influenza A virus infection in Brazilian swine herd following the introduction of pandemic 2009 H1N1. Veterinary Microbiology 180, 118-122.

Corzo, C. A., Culhane, M., Dee, S., Morrison, R. B., Torremorell, M., 2013. Airborne detection and quantification of Swine Influenza A virus in air samples collected inside, outside and downwind from swine barns. Plos One 8, pp. 1-7.

Dias, A.S., Costa, E.A., Rajao, D.S., Guedes, R.M., Ciacci Zanella, J.R., Lobato, Z.I., 2015. Distribution of antibodies against influenza virus in pigs from farrow-to-finish farms in Minas Gerais state, Brazil. Influenza Other Respiratory Viruses 9, pp. 161-167.

Fablet, C., Simon, G., Dorenlor, V., Eono, F., Eveno, E., Gorin, S., Quéguiner, S., Madec, F., Rose, N., 2013. Different herd level factors associated with $\mathrm{H} 1 \mathrm{~N} 1$ or $\mathrm{H} 2 \mathrm{~N} 1$ influenza virus infections in fattening pigs. Preventive Veterinary Medicine 112, pp. 257-265.

Jeong, K., Park, Y., Jin, W., Hee Han, J., 2007. Seroprevalence of swine influenza and porcine reproductive and respiratory syndrome in Korea. Korean Journal of Veterinary Service 30, pp.197-203.

Loeffen, W. L. A., Nodelijk, G., Heinen, P. P, Van Leengoed, L.A.M.G., Hunneman, W. A., Verheijden, J. H. M., 2003, a. Estimating the incidence of influenza-virus infection in Dutch weaned piglets using blood samples from a cross-sectional study. Veterinary Microbiology 91, 295-308.

Loeffen, W. L. A., Heinen, P. P., Bianchi, A. T. J., Hunneman, W. A., Verheilden, J. H. M., 2003, b. Effect of maternally derived antibodies on the clinical signs and immune response in pigs after primary and secondary infection with an influenza H1N1 virus. Veterinary Immunology and Immunopathology 92, pp.23-35.

Loeffen, W. L. A., Hunneman, W. A., Quak, J., Verheijden, J. H. M., Stegemen, J. A. 2009. Population dynamics of swine influenza virus in farrow-to-finish and specialized finishing herds in the Netherlands. Veterinary Microbiology 137, pp. 45-50.

López-Robles, G., Montalvo-Corral, M., Burgara-Estrella, A., Hernández, J., 2014. Serological and molecular prevalence of swine influenza virus on farms in northwestern Mexico. Veterinary Microbiology 172, pp. 323-328

Mancini, D. A. P., Mendonça, R.M.Z., Dias, A. L. F., Castro, A. F., Pinto, J. R., Mendonça, R. Z., 2006. Evidence of swine respiratory infection by influenza viruses in Brazil. Virus Review \& Research 11, pp. 39-43.

Olsen, C. W., 2002. The emergence of novel swine influenza viruses in North America. Virus Research 85, pp. 199-210.

Poljak, Z., Dewey, C. E., Martin, S. W., Chrostense, J., Carman, S., Friendship, R. M., 2008. Prevalence and risk factor for influenza in southern Ontario swine herds in 2001 and 2003. The Canadian Journal of Veterinary Research 72, pp. 7-17.

São Paulo - São Paulo state Agriculture and Food Supply office, 2008. Agricultural census of productive units in the São Paulo State. Integral Technical Assistance Coordination. Jaboticabal, São Paulo, Brazil.

Schaefer, R., Ciacci-Zanella, J. R., Brentano, L., Vincent, A. L., Ritterbusch, G. A., Silveira, S., Caron, L., Mores, N., 2011. Isolation and characterization of a pandemic H1N1 influenza virus in pigs in Brazil. Pesquisa Veterinária Brasileira 31, pp.761-767

Schaefer, R., Rech, R. R., Gava, D., Cantão, M. E., Silva, M. C., Silveira, S., Ciacci-Zanella, J. R., 2015. A human like H1N2 influenza virus detected during an outbreak of acute respiratory disease in swine in Brazil. Archives of Virology 160, pp.29-38. 
Simon-Grifé, M., Martín-Valls, G. E., Vilar, M. J., García-Bocanegra, I., Mpra, M., Martín, M., Mateu, E., Casal, J., 2011. Seroprevalence and risk factors of swine influenza in Spain. Veterinary Microbiology 149, pp. 56-63.

Thacker, E. L., 2001. Immunology of the Porcine Respiratory Disease Complex. Veterinary Clinics of North America and Food Animal Practice 17, pp. 551-563.

Thrusfield, M. V., 2010. In: Veterinary Epidemiology. Third edition. Blackwell Publishing, London, England.

Van Reeth, K., Brown, I. H., Olsen, C. W., 2012. Influenza Virus. In: Diseases of Swine, Tenth Ed. Blackwell-Wiley, Ames, Iowa, USA, pp. 557-551.
Vincent, A. L., Lager, K. M., Janke, B. H., Gramer, M. R., Richt, J. A., 2008. Failure of protection and enhanced pneumonia with US H1N2 swine influenza virus in pigs vaccinated with an inactivated classical swine H1N1 vaccine. Veterinary Microbiology 126, pp. 310-323.

Wesley R. D. 2004. Exposure of seropositive gilts to swine influenza virus may cause a few stillbirths per litter. Canadian Journal of Veterinary Research 68, pp. 215-217.

World Organization for Animal Health (2009). Swine Influenza. OIE Bulletin, OIE, Paris, France, pp 1-5. 